\title{
Enantioselective epoxidation of 1-hexene with sugar derived hydroperoxides
}

\author{
H.-J. Hamann ${ }^{\text {a }}$, M. Chmielewskib ${ }^{\text {, D. Mostowicz, }}$, and J. Liebscher ${ }^{\text {* }}$ \\ ${ }^{a}$ Institute of Chemistry, Humboldt University, Brook-Talyor-Straße 2, D-12489 Berlin, Germany \\ ${ }^{b}$ Institute of Organic Chemistry, Polish Academy of Sciences, Warsaw, Poland \\ E-mail: liebscher@chemie.hu-berlin.de
}

Dedicated to Prof. Dr. Berhanu M. Abegaz on the occasion of his $60^{\text {th }}$ birthday

\begin{abstract}
The catalyzed asymmetric epoxidation of 1-hexene with various optically active hydroperoxides derived from sugars has been examined in the presence of an achiral molybdenum-complex. Enantioselectivities up to $53 \%$ e. e. were achieved.
\end{abstract}

Keywords: Asymmetric Synthesis, epoxidation, hydroperoxides

\section{Introduction}

The asymmetric oxidation of unfunctionalized as well as functionalized olefins is the subject of intensive research in organic synthesis. ${ }^{1}$ Recently we described the asymmetric epoxidation of allylic alcohols and the oxidation of sulfides to sulfoxides with optically active sugar hydroperoxides. ${ }^{2,3,4}$ Enantioselectivities up to $50 \%$ e. e. were observed. Because the Jacobsen method ${ }^{1}$ using Mn-salen-complexes works highly efficient only for cis-substituted olefins the epoxidation of unfunctionalized olefins is still a great challenge in asymmetric oxidation. In order to approach this problem we investigated the epoxidation of terminal olefins with sugar derived hydroperoxides in the presence of Mo-catalyst such as $\mathrm{MoO}_{2}(\mathrm{acac})_{2}$ or $\mathrm{Mo}(\mathrm{CO})_{6}$. Unfortunately, these complexes were active only at temperatures above $80^{\circ} \mathrm{C}$. Thus no significant enantioselectivity could be detected under these conditions. ${ }^{5}$ Recently, Herrmann et al. described new dioxo-molybdenum(VI)-complexes of the type $\mathrm{MoO}_{2} \mathrm{~L}_{2}$ ( $\mathrm{L}=2$ - pyridinyl alcoholate), e.g. 9 and their application as catalysts for the oxidation of terminal n-alkenes with molecular oxygen and hydroperoxides. ${ }^{6}$ 


\section{Results and Discussion}

Here we report our results in the asymmetric epoxidation of 1-hexene by optically active sugar derived hydroperoxides in the presence of such a Mo-complex 9. ${ }^{7} 1$-Hexene was epoxidized by the sugar derived hydroperoxides 1-8 in the presence of catalytic amounts of $\mathbf{9}$ in $\mathrm{CH}_{2} \mathrm{Cl}_{2}$ at r.t. according to Scheme 1.

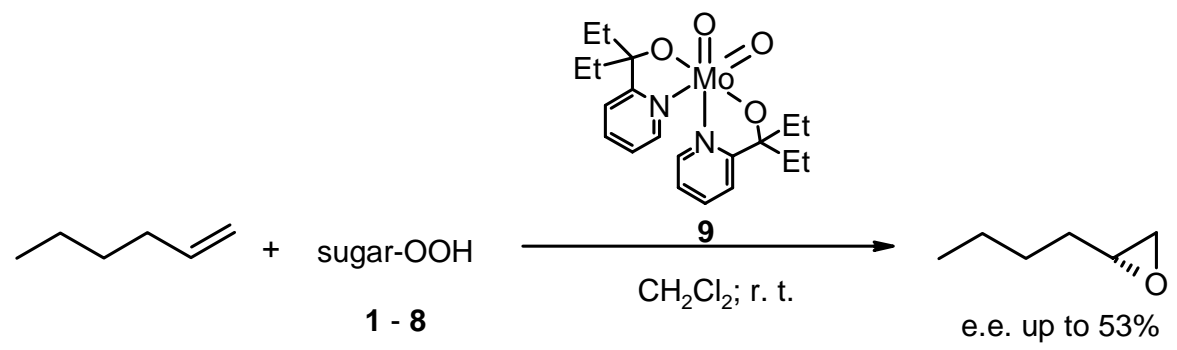

\section{Scheme 1}

The conversion of the hydroperoxides was complete within 3 days as determined by TLC. The e.e. of the epoxyhexane formed was determined in the reaction mixture by GC on cyclodextrine chiral stationary phases. The results obtained are summerized in Table 1.

In all cases the $(R)$-epoxyhexane was formed as major enantiomer. It appears that the direction of asymmetric induction is not affected by the other chiral centres at the sugar hydroperoxide but by the configuration at the anomeric carbon atom to which the hydroperoxy group is bound. The lowest e.e. (up to 30\%) were detected with methylidenehydroperoxides 3 and 4 and the 2,3-unsaturated hydroperoxide 2. Moderate enantiomeric excesses were observed using saturated hydroperoxide 6, 7 and 8, while the highest enantioselectivity up to $53 \%$ e.e. was achieved with compounds $\mathbf{1}$ and 5. To the best of our knowledge this is the best outcome in asymmetric epoxidation of a terminal unfunctionalized olefin so far. 
Table 1. Enantioselective epoxidation of 1-hexene with sugar derived hydroperoxides 1 - 8

\% e.e. ${ }^{\text {a }}$ \% e.e. ${ }^{\text {a }}$

${ }^{a}$ Determined by GC on a chiral stationary phase LIPODEX E (25 m x $0.25 \mathrm{~mm}$, $40{ }^{\circ} \mathrm{C}$, carrier gas: hydrogen, 0.3 bar) using a HP 5890 series II gas chromatograph with a split injector and FID.

\section{Experimental Section}

General Procedure. All reaction were carried out using hydroperoxide 1-8 (0.1 mmol), 1hexene $(0.1 \mathrm{mmol})$ and $10 \mathrm{~mol} \%$ Mo-catalyst 9 in dichloromethane at r.t. After complete conversion of the hydroperoxide (detected by TLC) the e.e. of the epoxyhexane formed was estimated in the resulting reaction mixture by GLC on LIPODEX E. Peak assignment to the $(R)$ and $(S)$ configuration was possible by comparison with an authentic sample from ALDRICH. 


\section{Acknowledgements}

This work was financially supported by the Deutsche Forschungsgemeinschaft (Schwerpunktprogramm: ”Sauerstofftransfer/Peroxidchemie”)

\section{References and Notes}

1. Jacobsen, E. N. In Comprehensive Organometallic Chemistry II, Abel, E. W.; Stone, F.G.A.; Wilkinson, G. Eds., Vol.12, pp 1097-1132, Pergamon: Oxford, 1995.

2. Hamann, H.-J.; Höft, E.; Chmielewski, M.; Maciejewski, S. Chirality 1993, 5, 338.

3. Hamann, H.-J.; Höft, E.; Mostowicz, D.; Mishnev, A.; Urbanczyk-Lipkowska, Z.; Chmielewski, M. Tetrahedron 1997, 53, 185.

4. Mostowicz, D.; Jurczak, M.; Hamann, H.-J.; Höft, E.; Chmielewski, M. Eur J. Org. Chem. 1998, 2617.

5. Hamann, H.-J.; Höft, E.; "Peroxide Chemistry: Mechanistic and Preparative Aspects of Oxygen Transfer”, Meeting of the Deutsche Forschungsgemeinschaft, Freyburg/Unstrut, Germany, 20-22 September 1995.

6. Herrmann, W. A.; Lomaier, G. M.; Priermeier, T.; Mattner, M. R.; Scharbert, B. J. Mol. Catal. 1997, 117, 455.

7. Hamann, H.-J.; Höft, E.; "Peroxide Chemistry: Mechanistic and Preparative Aspects of Oxygen Transfer”, Meeting of the Deutsche Forschungsgemeinschaft, Köln, Germany, 2830 September 1997. 